Supplement of Ocean Sci., 14, 827-847, 2018

https://doi.org/10.5194/os-14-827-2018-supplement

(C) Author(s) 2018. This work is distributed under

the Creative Commons Attribution 4.0 License.

Ocean Science

(c) (1)

Supplement of

\title{
Impact of HF radar current gap-filling methodologies on the Lagrangian assessment of coastal dynamics
}

Ismael Hernández-Carrasco et al.

Correspondence to: Ismael Hernández-Carrasco (ismaelhe@gmail.com)

The copyright of individual parts of the supplement might differ from the CC BY 4.0 License. 


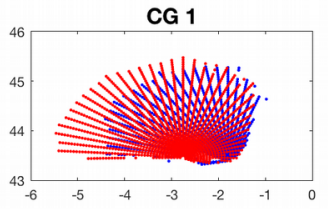

CG 5

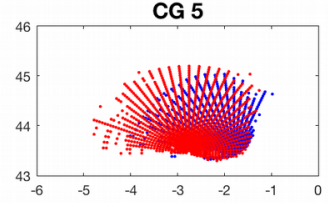

CG 9

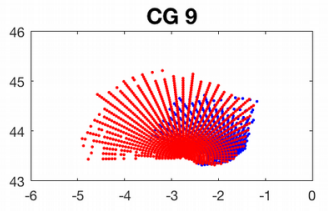

CG 13

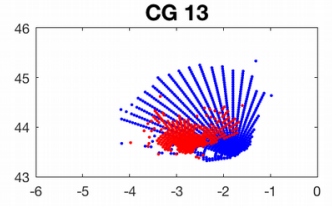

CG 2

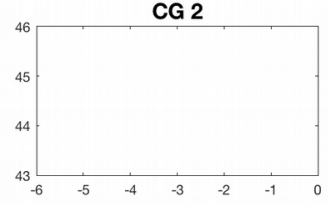

CG 6

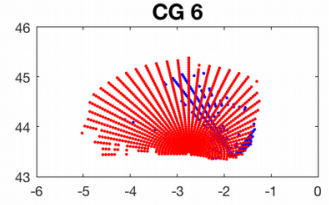

CG 10

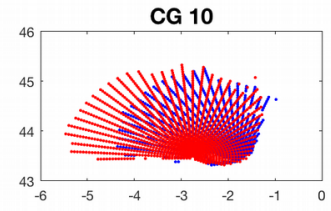

CG 14

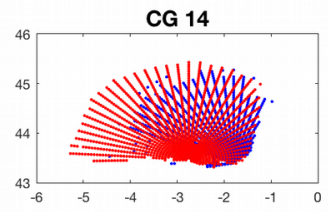

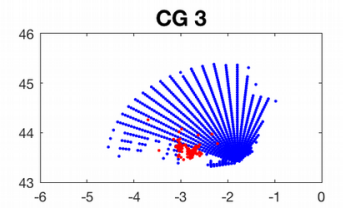

CG 7

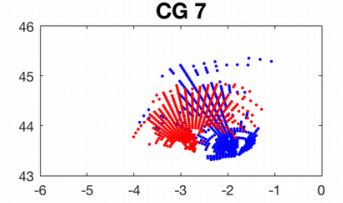

CG 11

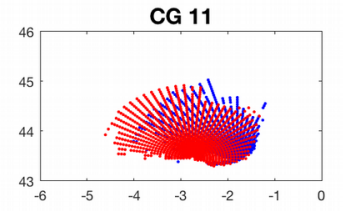

CG 15

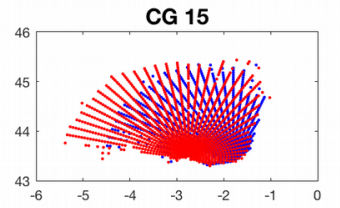

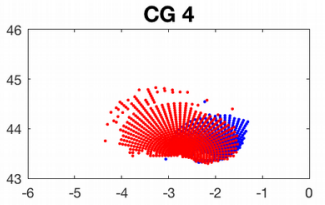

CG 8

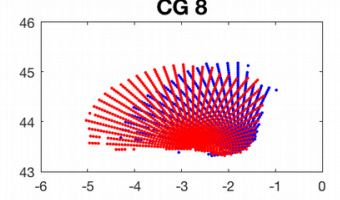

CG 12

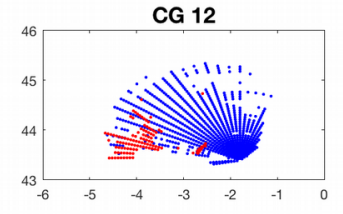

CG 16

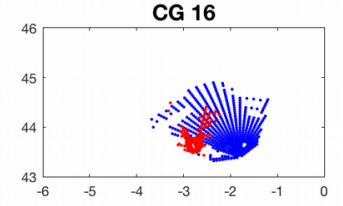

Figure S1. Complete prototypes of groups of gap distribution scenarios obtained by the KMA analysis applied to HFR availability-absence matrix for 2014. 